\title{
Construindo pontes: a prática da interdisciplinaridade. \\ Estudo PopTrans: um estudo com travestis e mulheres transexuais em Salvador, Bahia, Brasil
}

\section{Building bridges: interdisciplinarity in practice. PopTrans Study: a study with transvestites and transsexual women in Salvador, Bahia State, Brazil}

\author{
Construyendo puentes: la práctica de la \\ interdisciplinaridad. Estudio PopTrans: un \\ estudio con travestis y mujeres transexuales \\ en Salvador, Bahía, Brasil
}

Ines Dourado 1 Luís Augusto V. da Silva 1,2

Laio Magno 1,3

Maycon Lopes 1

Caio Cerqueira 1

Adriana Prates 1

Sandra Brignol 4

Sarah MacCarthy 5

\section{Resumo}

Pessoas trans, incluindo travestis, mulheres transexuais, apresentam taxas desproporcionalmente elevadas de HIVIAIDS em comparação com o restante da população. Entretanto, são poucos os estudos quantitativos/ qualitativos com pessoas trans no Brasil. Assim, uma equipe de pesquisadores de diferentes áreas desenvolve um projeto de pesquisa interdisciplinar com o objetivo de conhecer as condições e os modos de vida, e ao mesmo tempo investigar fatores determinantes da infecção pelo HIV, sífilis e hepatites B e C entre travestis e mulheres transexuais. Neste artigo, pretende-se descrever a experiência de implantação e desenvolvimento do estudo com uma abordagem etnoepidemiológica em Salvador, Bahia, Brasil. O mapeamento da população começou com uma pesquisa formativa que foi crucial para orientar o inquérito epidemiológico. A produção de

1 Instituto de Saúde Coletiva, Universidade Federal da Bahia, Salvador, Brasil. 2 Instituto de Humanidades, Artes e Ciências, Universidade Federal da Bahia, Salvador, Brasil.

${ }^{3}$ Departamento de Ciências da Vida, Universidade do Estado da Bahia, Salvador, Brasil.

${ }^{4}$ Instituto de Saúde Coletiva, Universidade Federal

Fluminense, Niterói, Brasil.

5 RAND Corporation, Santa

Monica, U.S.A.

\author{
Correspondência \\ I. Dourado \\ Instituto de Saúde Coletiva, \\ Universidade Federal da \\ Bahia. \\ Rua Basílio da Gama s/n, \\ Salvador, $B A$ \\ 40110-040, Brasil. \\ ines.dourado@gmail.com
} dados etnoepidemiológicos é um desafio cotidiano para os pesquisadores, produzindo uma série de reflexões sobre os limites de nossos conceitos e categorias para traduzir a diversidade de práticas e experiências das participantes da pesquisa.

Transexuais; HIV; Síndrome de Imunodeficiência Adquirida;

Pesquisa Interdisciplinar 


\section{Introdução}

A saúde de pessoas trans, incluindo travestis, mulheres transexuais e pessoas cuja identidade de gênero difere das expectativas sociais (estas orientadas pelo "sexo" atribuído no nascimento), tem recebido crescente atenção mundial, como mostram relatórios de alguns países, inclusive do Institute of Medicine (IoM) dos Estados Unidos em 2011 1, e a recente Política Nacional de Saúde Integral de Lésbicas, Gays, Bissexuais, Travestis e Transexuais no Brasil 2. Dados publicados fora do país demonstram que essa população apresenta necessidades de saúde específicas e importantes, além de taxas desproporcionalmente mais elevadas de HIV e outras infecções sexualmente transmissíveis (IST) em comparação com o restante da população $3,4,5,6,7,8,9,10$. Além disso, pessoas trans, considerando os diversos posicionamentos identitários que borram a dicotomia sexo/ gênero, podem apresentar uma combinação de fatores de risco e situações de vulnerabilidade para IST, tais como: condições socioeconômicas desfavoráveis (quando sua identidade de gênero aparece interseccionada a um contexto de pobreza), itinerários de transformações corporais sem acompanhamento médico, práticas sexuais de risco (sobretudo aquelas que trabalham no mercado do sexo), além de estigma e violência (transfobia) 11,12,13,14.

Ainda são poucos os estudos interdisciplinares que agregam métodos quantitativo e qualitativo com pessoas trans, principalmente no Brasil. Especificamente no cenário brasileiro, esses estudos são majoritariamente oriundos das ciências sociais e humanas; alguns deles com consideráveis contribuições para o campo da Saúde Coletiva, ao discutirem os avanços e limites no processo transexualizador no SUS 15,16,17, bem como a pauta de despatologização da transexualidade 18,19. Esses estudos apontam também a fluidez e instabilidade das categorias identitárias de travesti e transexual. Segundo Lionço 15 (p. 54), travestis e transexuais "se constituem subjetivamente como indivíduos pertencentes a um gênero que não corresponde linearmente ao sexo de nascimento". Entretanto, as travestis sustentam uma "ambiguidade ou duplicidade sexual na própria afirmação identitária” 15 (p. 54). Por outro lado, como enfatizam Arán \& Murta 17, muitas vezes as fronteiras/distinções entre travestis e transexuais encontram-se borradas no cotidiano, havendo um trânsito entre estas identidades. Portanto, não são fixas ou isoladas, mas posições sempre disputadas, negociadas, em constante interação e movimento.

Diante desse cenário, uma equipe de pesquisadores de diferentes instituições de Ensino
Superior (profissionais de saúde coletiva e cientistas sociais), militantes dos movimentos sociais de travestis e transexuais em Salvador, Bahia, Brasil, e atores governamentais têm se reunido, desde 2010, para desenvolverem um projeto de pesquisa: Estudo PopTtrans - Vulnerabilidade ao HIVIAids, Sífilis e Hepatites Virais na População de Travestis e Mulheres Transexuais e seus Modos de Vida em Salvador-Bahia, com o objetivo de conhecer as experiências identitárias, condições e modos de vida e investigar fatores determinantes da infecção pelo HIV, sífilis e hepatites virais na população de travestis e mulheres transexuais, em Salvador.

Para o desenvolvimento da pesquisa, partiuse de um desenho que viabilizasse a produção de dados quantitativos (inquérito epidemiológico), bem como dados qualitativos (produzidos por meio de observação participante, grupos focais e entrevistas semiestruturadas) referentes às travestis e mulheres transexuais. Pretendia-se, portanto, trabalhar com uma metodologia que considerasse a cooperação de distintos pesquisadores, a integração de métodos variados, bem como a interação coerente e criativa de distintas técnicas para a produção de dados e conhecimento científico. Dessa forma, trazemos, neste artigo, o processo coletivo de construção da pesquisa, com o objetivo de apresentar o percurso e lições aprendidas na concepção e condução do projeto. Pretendemos, também, enfatizar a pesquisa como um processo de mediação coletiva, cujos dados são produzidos usando-se técnicas/tecnologias, negociações, traduções, participações, interações e, finalmente, estabilizações provisórias 20 .

\section{Caminhos metodológicos: algumas reflexões etnoepidemiológicas}

\section{A etnoepidemiologia}

A pesquisa em curso combina abordagens epidemiológicas e socioantropológicas, chamadas por vários autores de etnoepidemiologia, no sentido de articular diferentes métodos e técnicas de pesquisa 21,22,23,24. Entretanto, para além da integração ou articulação de diferentes linguagens e tradições metodológicas, este trabalho parte de uma reflexão crítica sobre a necessidade de maior diálogo da epidemiologia com outros saberes e práticas socioculturais. Como sugere Samaja 25 (p. 33), esta é uma proposta de interlocução que parte do pressuposto de que " $a$ saúde/ doença é, desde sempre, um fenômeno semióticocomunicacional, uma instância de sentido significativa para sujeitos da cultura, e não apenas um fenômeno natural". 
Certamente, conforme apontam alguns autores 21,26, a abordagem etnoepidemiológica, além de pensar uma epidemiologia que seja antropologicamente referenciada, tomando diferenças socioculturais como indicadores de fatores de risco ou proteção, ou mesmo partindo da compreensão de que as pessoas criam, compartilham, organizam e usam um conhecimento comum (semiologia popular) sobre a doença, deve ser capaz de incorporar uma maior reflexividade sobre a ciência epidemiológica, pensando-a também como uma prática social, mediada pelas circunstâncias de sua produção, pela história e por uma heterogeneidade de atores (humanos e não humanos) que interagem e se afetam mutuamente. Aqui, utilizamos a palavra ator no sentido latouriano para nos referir a "qualquer coisa que modifique uma situação fazendo diferença” 27 (p. 108)

Dessa forma, para além da dicotomia pesquisa qualitativa versus quantitativa, ao colocar a natureza socialmente construída da realidade de um lado, e o ato de medir e de analisar as relações causais entre variáveis do outro ${ }^{28}$, buscou-se focalizar uma prática de pesquisa aberta a novos "modelos interpretativos" do complexo saúdedoença-cuidado, capaz de articular diferentes métodos, estratégias e técnicas de investigação, considerando as indefinições, historicidade e ambiguidades destes fenômenos. Por sua vez, devese considerar também nesta abordagem o cotidiano diverso em que ocorrem e são traduzidos esses processos (de saúde-doença-cuidado), com o objetivo de pensar e problematizar sobre os próprios limites e desafios da produção científica.

\section{O processo de integração de métodos}

A escolha pela etnoepidemiologia exigiu dos pesquisadores um exercício contínuo de interdisciplinaridade. Desde a concepção do estudo vêm ocorrendo inúmeras discussões que intentam articular a demanda por dados epidemiológicos aos modos de vida de pessoas travestis e mulheres transexuais. Diversas foram as discussões (e embates) de natureza teórico-metodológica ocorridas entre pesquisadores de distintas linguagens e trajetórias. Assim, o percurso de conformação do trabalho, por meio das interações e tensões entre pesquisadores, agências governamentais, interlocutores/as, colaboradores/as, instrumentos/modelos de pesquisa e perspectivas teóricas, configurou-se como uma profícua experiência de aprendizagem e exercício concreto de transgressão dos limites das próprias disciplinas nas quais atuamos.

Vale também destacar o longo e por vezes infindável processo de construção do questio- nário, instrumento do inquérito epidemiológico, que também envolveu conflitos e negociações entre integrantes da equipe, uma vez que, não raro, muitas questões suscitavam debates de ordem política (por exemplo, o que significava ser travesti, transexual, ou mesmo sobre as implicações no uso das categorias "sexo" e "gênero"). Estávamos, pois, engajados na difícil tarefa de compor um mundo comum 29. No decorrer do processo de escolha dos blocos temáticos e perguntas, desde como enunciá-las, a equipe levou em consideração uma gama de aspectos éticos e culturais, em conciliação com os objetivos aos quais o projeto visava atender e com as próprias limitações e acomodações exigidas por um instrumento estruturado com questões fechadas. Permeado por um sem-número de "idas e vindas", a discussão da literatura e o diálogo com áreas diversas foram parte crucial do percurso de elaboração e refinamento do questionário. Nesse percurso, também foi imprescindível a participação de ativistas travestis e mulheres transexuais na revisão do questionário, como também de outras travestis e mulheres transexuais no momento de aplicação de um "piloto"- momento este em que novas questões foram colocadas ou requalificadas.

De acordo com essas reflexões etnoepidemiológicas, diferentes estratégias e técnicas da pesquisa qualitativa foram sendo incorporadas, não apenas para melhor traduzir os dados epidemiológicos, mas também com o objetivo de focalizar as dimensões simbólica, intersubjetiva e contextual do cotidiano das travestis e mulheres transexuais, que não podem ser meramente transpostas ou traduzidas em números, como, por exemplo: suas trajetórias de modificação corporal - por vezes bastante irregulares e intermitentes - suas experiências de sociabilidade, violência/transfobia e afetivo-sexuais.

A combinação dessas distintas abordagens e técnicas de pesquisa (qualitativa e quantitativa) ocorreu ao longo de todo o curso da investigação. Por exemplo, em relação ao inquérito epidemiológico, que produziu dados socioeconômicos e demográficos sobre práticas e comportamento sexual e de uso de álcool e outras drogas, dados de modificações no corpo com o uso de hormônios e silicone, situações de violência, estigma e encarceramento, acesso a serviços públicos de saúde, além dos resultados dos testes sorológicos para HIV, sífilis e hepatites virais, foi necessário desenvolver uma aproximação com pessoas travestis e mulheres transexuais na cidade de Salvador, buscando "mapear" aspectos importantes (descritos a seguir) de seu cotidiano para a realização do estudo e, mais precisamente, para utilizar uma técnica de amostragem indicada para 
populações de difícil acesso: o respondent driven sampling (RDS) 30,31,32,33.

Esse método consiste em um recrutamento de indivíduos que estão inseridos em uma mesma rede pessoal de relacionamentos ou "rede social". Baseia-se no reconhecimento de que os pares são, em comparação com os pesquisadores, melhores recrutadores de indivíduos da populaçãoalvo. Além disso, esse método visa à formação de uma amostra com menos vieses do que nas amostras por conveniência, nas quais as escolhas são feitas diretamente pelos pesquisadores ou integrantes da equipe de pesquisa. Vários estudos com o RDS já foram realizados no Brasil entre as chamadas "populações-chave" para a epidemia de AIDS 34,35,36. Populações-chave, segundo o Programa Global de AIDS (UNAIDS), são grupos definidos que, devido a comportamentos específicos, aumentam a sua vulnerabilidade para a infecção pelo HIV e outras IST, tornando-se populações prioritárias para as políticas de prevenção, diagnóstico e tratamento do HIV e outras IST 37.

Na trilha das travestis e mulheres transexuais: o cotidiano da pesquisa

Conforme antecipado, para viabilizar o trabalho de campo foi fundamental mapear como e onde algumas travestis e mulheres transexuais viviam na cidade de Salvador. O primeiro passo dessa aproximação foi pelo contato com travestis e mulheres transexuais do movimento social e/ ou conhecidas da equipe do projeto, para saber qual a melhor forma de comunicação com elas. Em seguida, iniciamos um mapeamento por intermédio de: redes sociais on-line, nosso "campo virtual"; eventos LGBT, como as paradas gays que acontecem ao longo do ano nos bairros, sobretudo nas "periferias" da cidade; manifestações orquestradas pelos movimentos sociais em defesa de direitos desta população; solicitação de contatos (telefones/e-mails) das travestis e mulheres transexuais que foram encontradas em diferentes locais da cidade pelos membros da equipe; $\mathrm{e}$ contatos potenciais indicados por outras pessoas (colegas, comerciantes, alunos da universidade, pesquisadores etc).

Ao contatar as travestis e mulheres transexuais, exceto para o campo virtual, entregávamos um postal com as informações sobre o projeto e com um espaço destacável onde elas voluntariamente disponibilizavam seu contato on-line e/ou telefônico. Conforme será descrito adiante, essas sucessivas aproximações foram relevantes para revisarmos os instrumentos e técnicas de pesquisa, ao tempo em que a equipe produzia maior familiaridade com as travestis e mulheres transexuais.
Trabalho de campo virtual (Internet, aplicativos e telefone)

Para viabilizar e facilitar os contatos, utilizamos sempre o nome fantasia do projeto - Projeto PopTrans - e um logotipo, além disto, criamos um perfil no Facebook (http://www.facebook.com/ poptrans) a fim de estabelecer vínculos, informar os objetivos da pesquisa e apresentar sua equipe. Uma das estratégias das quais lançamos mão para nos aproximar de nossas interlocutoras foi por meio da divulgação de notícias de "utilidade pública" que interessam às travestis e mulheres transexuais. Vale assinalar que essas divulgações não foram apenas estratégias de aproximação, mas também parte de certa responsabilidade social assumida pelo grupo de pesquisa, uma vez que nem todas as travestis e mulheres transexuais estão inseridas nas redes do movimento social LGBT, por onde, principalmente, circulam tais informações.

Valendo-se das interações on-line, explicava-se a forma de participação e recrutamento no projeto, dias, horário e local de funcionamento, o ressarcimento que seria ofertado a cada participante pelo tempo dedicado à pesquisa (via vale-alimentação), a disponibilização de insumos (como preservativos e gel lubrificante) e a oportunidade de realização de teste rápido para HIV, sífilis e hepatites virais B e C. Essas interações foram importantes para conhecer melhor em que medida os produtos e serviços oferecidos eram passíveis de despertar e mobilizar interesse.

Ao falar sobre o propósito da pesquisa, foi bastante comum a produção de relatos, por parte das travestis e mulheres transexuais, de situações concretas enfrentadas no cotidiano, que variam desde a incompreensão e preconceito de profissionais de saúde, às dificuldades inerentes à conquista de emprego no mercado de trabalho formal. Falavam, ainda, sobre o relacionamento com familiares, uso de hormônios, sociabilidade com outras travestis/transexuais, planos para viajar para a Europa, envelhecimento e sobre diversas outras temáticas que circunscrevem o "universo travestis e mulheres transexuais". O Facebook foi uma ferramenta que possibilitou a criação de certa empatia entre o projeto (que na rede responde pelo nome de Linda Salvador) e as participantes do nosso estudo. Algumas dessas conversas aconteceram também no WhatsApp, na medida em que algumas travestis e mulheres transexuais preferiam conversar pelo aplicativo.

Vale ressaltar que, ao tentar estabelecer contato com travestis e mulheres transexuais adicionadas ao Facebook, encontramos resistência por parte de algumas, que suspeitavam que fôssemos homens buscando tirar algum proveito de- 
las. Como estratégia para contornar tais dificuldades, disponibilizamos no nosso perfil fotografias da equipe dinamizadora do projeto, algumas das quais feitas em eventos LGBT e acompanhadas de lideranças do movimento social e outras travestis e mulheres transexuais em evidência. Acreditamos que isso tenha conferido mais credibilidade ao perfil e contribuído para dissolver certa desconfiança. Embora não tenha efetuado trabalho de campo on-line, Kulick 38 , em etnografia realizada com travestis de Salvador na década de 1990, menciona que grande parte das travestis demonstrava certa desconfiança na interação com outras pessoas - não apenas com ele - tendo o autor atribuído tais características à violência e discriminação cotidiana a que eram expostas. Outros autores também comentam sobre a desconfiança das travestis e mulheres transexuais em suas relações sociais 39,40 .

Além disso, desenvolvemos um primeiro instrumento de produção de dados denominado Roteiro 1- Identificação das Travestis e Mulheres Transexuais e de suas Redes de Contato, com informações bem sucintas, como idade, ocupação, lugares que frequentavam, com quantos outras travestis e mulheres transexuais da cidade mantinham contato, bem como a forma com que se autoidentificavam (se travesti, transexual etc.) e sobre uso de hormônio e/ou silicone, para uma conversa com os contatos realizados no mapeamento. Por telefone, contatamos 94 travestis e mulheres transexuais cujas informações produzidas foram organizadas em uma planilha Excel (Microsoft Corp. Estados Unidos), denominada de Planilha de Contatos. Novamente a dificuldade de contato foi observada quando algumas não atendiam ao telefone, forneceram número incorreto, ou ignoravam as mensagens deixadas nas redes sociais.

\section{Grupos focais e pesquisa piloto}

O mapeamento inicial foi fundamental para dar seguimento à realização dos grupos focais, com o objetivo mais específico de pensar, conjuntamente, estratégias e limites de utilização do RDS e da testagem sorológica para o estudo, mas também produzir maior familiaridade com os aspectos do cotidiano de pessoas travestis e mulheres transexuais em Salvador. Foram realizados dois grupos focais, com travestis e mulheres transexuais ativistas, profissionais do sexo, entre outras.

As questões abordadas nesses grupos focais, após a apresentação detalhada do projeto, foram importantes para problematizar aspectos diversos do cotidiano da pesquisa com esta população, entre eles: dificuldades de recrutamento e engajamento em projetos de pesquisa, questões éticas envolvidas na maneira de aconselhamento, divulgação do resultado sorológico e interação com os serviços de saúde, dimensões simbólicas do HIV/AIDS e a centralidade de outras questões da vida travestis e mulheres transexuais (construção identitária e modificação corporal, por exemplo).

No que diz respeito à realização dos testes rápidos, a discussão em ambos os grupos focais se deteve no tipo do teste e na entrega do resultado. A percepção geral foi de que o teste rápido é bom, mas este não deveria ser entregue no mesmo dia para as participantes do estudo. Um dos grupos focais destacou que, quando se tratasse de alguma profissional do sexo, deveria haver um cuidado ainda maior na revelação do resultado, devido à grande competição entre elas por clientes. $\mathrm{O}$ mesmo apareceu para aquelas que moram em "casa de travestis" (no questionário, por orientação do movimento social, a expressão "casa de cafetina" foi substituída por "casa de travestis", devido ao seu teor clandestino), pois poderiam ser despejadas e/ou sofrer discriminação. Os grupos focais ressaltaram a necessidade de aconselhamento pré e pós-teste por conta do "medo" do resultado "positivo" para o HIV.

Um pré-teste (piloto) do questionário foi realizado com duas travestis e mulheres transexuais orientando a revisão de algumas questões. Um aspecto importante que chamou a atenção foi que, embora o termo "homossexual" possivelmente seja conhecido pelas travestis e mulheres transexuais, a categoria "orientação sexual" parece não fazer parte do seu vocabulário. Por outro lado, ao contrário do que sugerem os trabalhos sobre as travestis $41,42,43$, nem todas que assim se identificam parecem saber o significado do termo "bombadeira", que designa outra pessoa que participa das ações de modificação corporal da travestis e mulheres transexuais aplicando-lhes injeções de silicone industrial. Em geral, as bombadeiras são travestis, mas às vezes são mulheres cisgêneras; isto é, mulheres cuja identidade de gênero é consoante ao gênero designado quando do seu nascimento. Assim, para o caso da necessidade de esclarecimentos, incluímos também o termo bombadeira no manual de instruções para auxiliar o/a responsável pela aplicação do questionário.

Com base no piloto, que nos possibilitou discutir até que ponto estávamos conseguindo comunicar, revisitamos os objetivos do nosso projeto e, assim, reavaliamos a pertinência e inteligibilidade de algumas questões. Um esforço coletivo em busca de "tradução" de culturas, tradições e linguagens. Nessa perspectiva, a aplicação de um questionário (com perguntas e respostas) também ocorre em um espaço interativo 20 , 
situado histórico e culturalmente. É importante, assim, que se atente para as "técnicas de registro”, incluindo suas mediações tecnológicas, mas também para os usos e situações sociais dos enunciados: o preenchimento de um questionário ocorre no "interior de um diálogo", em uma "cadeia de comunicação na qual os interlocutores participamativamente da interação discursiva” 20 (p. 115).

\section{A seleção das "sementes"}

As primeiras aproximações on-line e off-line foram importantes para que pudéssemos selecionar seis travestis e mulheres transexuais (de forma não aleatória) para dar início ao recrutamento segundo a metodologia RDS, ou seja, as "sementes". Tal escolha ocorreu em função da amplitude da rede de contatos, diversidade territorial, ocupacional e etária das travestis e mulheres transexuais. Essas sementes iniciaram o recrutamento e suas convidadas formaram a primeira onda do recrutamento. Em razão das dificuldades encontradas por parte das "sementes" em recrutar suas conhecidas, foi necessário incluir novas travestis e mulheres transexuais com esta função - de acordo com a própria metodologia utilizada.

A faixa etária das travestis e mulheres transexuais que iniciaram o recrutamento variou entre 20 e 45 anos. A localização de suas residências também foi diversa, porém todas elas residiam em bairros designados "periféricos", e não se verificou grande variação na renda. Chegamos, ainda, a considerar como semente uma travesti que as próprias travestis e mulheres transexuais denominam “top" - expressão utilizada para uma travesti dotada de alto capital corporal (com prótese nos seios, encarnação de certo estilo fitness, mais próxima aos padrões convencionais de beleza feminina), que faz anúncio de serviços sexuais em sites, e que, desta forma, está protegida da violência a que se expõem aquelas que fazem da rua "vitrine". Seu capital corporal é revertido em capital econômico: essa travesti possui maior poder aquisitivo que as demais.

Contudo, observamos que essa "top", que desde o princípio nos pareceu menos acessível e pouco disposta a participar do estudo do que as demais travestis e mulheres transexuais, estava principalmente enredada em relações interpessoais com travestis de baixa renda. Fomos, assim, levados à conclusão não apenas de que as "tops" representam de fato uma minoria numérica quer dizer, poucas são aquelas que alcançam tamanho prestígio no mercado do sexo a ponto de serem designadas "top"- como não nos pareceu provável que elas viabilizariam o acesso a outras travestis e mulheres transexuais deste "grupo" de maior renda e poder de consumo.

Tivemos acesso também a "sementes" (e convidadas) que não fazem prostituição, ou seja, estão em algum curso superior, encontram-se conectadas na internet, o que nos possibilitou pensar em outros perfis identitários e possíveis mudanças no cenário travestis e mulheres transexuais no Nordeste brasileiro. Não podemos esquecer que a Internet possibilita a abertura para outras performances/ identidades, muitas vezes produzidas no anonimato, de uma forma mais descentrada, flexível e múltipla ${ }^{44}$. No que diz respeito também às relações entre tecnologias e usuários, devemos considerar a reciprocidade e os múltiplos efeitos destas interações 45 , podendo ocorrer transformações diversas: das tecnologias, dos usuários e de suas culturas.

Finalmente, é importante destacar que a análise de algumas redes sociais on-line nos ajudou na escolha de algumas "sementes". Essa análise ocorreu usando-se uma "ferramenta" possibilitada pelo Facebook: ao realizarmos o cruzamento de determinados perfis, tivemos acesso à quantidade de "amigos" em comum que as potenciais sementes possuíam entre si. Um dos critérios para escolhermos as sementes foi não somente a popularidade das mesmas, uma vez que isto pode implicar maior possibilidade de mobilização, como também a diversidade dessas redes, mensuráveis via "interseção" de contatos/amigos disponibilizada pelo Facebook.

\section{Implementação do inquérito e de entrevistas} em profundidade

Em relação ao inquérito epidemiológico, as participantes recrutadas e elegíveis (autodeclararam ser travestis e mulheres transexuais e concordaram em participar do estudo) passaram pela entrevista quantitativa e foram convidadas a fazer os testes para as IST. Aquelas que aceitaram fizeram aconselhamento pré e pós-teste. Esses procedimentos aconteceram em três salas de um prédio localizado em uma movimentada rua do Centro Histórico de Salvador e de fácil acesso por transporte público.

As salas da pesquisa foram divididas e decoradas de forma simples, porém aconchegante, amigável e adornadas com elementos que poderíamos caracterizar sob a rubrica de "cultura" ou "estética kitsch", a qual, grosso modo, é conhecida pela mistura de vários estilos, pela extravagância de cores, pela heterogeneidade e quase desarmonia entre os adornos dispostos no ambiente, que podem "passear" pelo sagrado, sensual ou tão-somente corriqueiro - sem nutrir necessária relação entre eles, por conseguinte 
mais próximos a signos que remetem a espaços ou "cultura" LGBT. Todo o ambiente foi concebido, portanto, não como um mero cenário no qual as ações ocorrem e a pesquisa ganha vida, mas com base em sua potencialidade em provocar certas disposições afetivas, quer dizer, de efetivamente atuar e suscitar a empatia das nossas interlocutoras.

No que diz respeito ao estudo qualitativo, entrevistas semiestruturadas, que abordaram diferentes temas, como identidade e corpo, itinerários terapêuticos/acesso aos serviços de saúde, estigma, violência e discriminação, sociabilidades e relacionamentos e projetos ou perspectivas para o futuro, também foram conduzidas com travestis e mulheres transexuais participantes do inquérito que foram convidadas e aceitaram participar de mais um momento do projeto. Com essas entrevistas em profundidade - além dos diários de campo, que todos/as pesquisadores/as de campo foram incentivados/as a desenvolver - buscou-se produzir narrativas sobre dimensões da vida como travestis e mulheres transexuais. Algumas dessas entrevistas foram realizadas no mesmo espaço do inquérito epidemiológico, e outras, em locais escolhidos pelas nossas interlocutoras.

Em reuniões coletivas, toda a equipe do projeto participava ativamente das discussões referentes às rotinas do campo, quando estratégias de recrutamento e de pesquisa eram discutidas e avaliadas com os coordenadores gerais. Alguns desses mesmos atores realizaram igualmente entrevistas do inquérito epidemiológico tanto quanto entrevistas em profundidade. Mesmo aqueles/as que realizaram apenas o "inquérito", ou estavam inseridos/as em alguma de suas rotinas (testagem, aconselhamento, recepção), foram orientados/as a registrar suas impressões do campo e indicar "potenciais" participantes para a produção de outras narrativas. Assim, esses nossos encontros foram um espaço também de tensão e negociação, na medida em que estudantes, pesquisadores e profissionais de saúde apresentavam diferentes perfis, experiências e trajetórias de formação. Entretanto, foram essas mesmas experiências (e conflitos) acumuladas no campo que permitiram ampliar a compreensão geral da pesquisa e dessa população.

\section{Lições aprendidas}

Conforme apontamos ao longo deste artigo, a produção de dados etnoepidemiológicos sobre as travestis e mulheres transexuais tem sido um desafio para o grupo de pesquisa. O retorno ao cotidiano, às linhas, direções e decisões que fo- ram tomadas no decorrer das interações e negociações entre atores diversos (que incluem as próprias travestis e mulheres transexuais), tem também o objetivo de refletir sobre os processos (desafios, limites e possibilidades) de comunicação entre culturas e linguagens (científicas e não científicas), considerando a arena transepistêmica 46 de produção de conhecimento. Destaca-se que essa reflexividade pode trazer para as análises e discussões epidemiológicas "as histórias, narrativas e sentidos de saúde-doença-cuidado, importantes para a compreensão dos modos de vida de indivíduos e grupos" 21 (p. 392).

Nesse sentido, as interações cotidianas com atores do movimento social e outras travestis e mulheres transexuais que circulam na cidade de Salvador, ou mesmo nos espaços on-line, têm produzido uma série de reflexões sobre as limitações de nossos conceitos/categorias para traduzir a diversidade de práticas e experiências. Por outro lado, são essas mesmas reflexões que possibilitam rever e expandir as linguagens e objetivos científicos materializados em nossos instrumentos de pesquisa. Vale destacar que a utilização do método RDS para a seleção de pessoas trans em estudos futuros deve considerar: a mobilidade das redes sociais travestis e mulheres transexuais, além do crescente uso de diferentes mídias, como as redes sociais on-line, que colaboram com o recrutamento das participantes do estudo.

Não podemos esquecer, também, os conflitos entre comunidade científica e não científica (movimento social de travestis e mulheres transexuais). Há tensões presentes entre os objetivos de pesquisa e demanda social, que, em vários momentos, devem ser discutidas e negociadas para viabilizar a própria pesquisa. Essas tensões mostram, assim, uma diversidade de interesses que se deslocam nesse cotidiano, como, por exemplo, a demanda das agências de pesquisa para a produção de conhecimento sobre a prevalência de HIV, as necessidades de sobrevivência e reconhecimento de pessoas travestis e mulheres transexuais em contextos diversos de discriminação e violência, e expectativas geradas pela própria pauta do projeto. Como algumas das nossas entrevistas mostram, muitas vezes é mais importante manter a atividade de modificação corporal, inclusive como uma forma de assegurar a sua existência no mundo, o reconhecimento de sua identidade, do que preocupar-se com o HIV/AIDS - que não lhes parece algo tão imediato e urgente quanto, por exemplo, o dinheiro necessário para pagar o aluguel no final do mês, ou a cada semana. Destacam-se também as tensões entre as categorias identitárias já utilizadas e reconhecidas por alguns atores (acadêmico- 
cientistas e do movimento social de travestis e mulheres transexuais no Brasil) e aquelas identidades mais fluidas, instáveis, do cotidiano.

Essa diversidade de interesses, experiências e práticas parece apontar para múltiplas versões da realidade. Como enfatiza Mol 47, com o conceito de "política ontológica", a realidade não precede as "práticas mundanas", mas é formada dentro destas práticas. Portanto, é múltipla. Assim, quando consideramos os diversos momentos e situações em que ocorre a participação/interação ou engajamento de tantos atores, incluindo materiais e tecnologias, a realidade não está mais "intocada no centro". Ainda que possamos fazer conexões (parciais), há pontos de fuga que indicam movimento, fluidez, mudança e transformação.

Finalmente, o esforço (coletivo) de trazer para este artigo algumas questões ou dimensões (práticas) do esforço de produção de conhecimento, em um estudo com diferentes abordagens de pesquisa, epidemiológica e socioantropológica, vai também na direção de colocar em pauta uma "simetria" possível entre campos disciplinares heterogêneos, o que talvez nos possibilite estabelecer "pontos" de contato ou conexões entre disciplinas consideradas tão antagônicas ou díspares. Dessa forma, ainda que haja produções (e interpretações) distintas, por exemplo, com "narrativas", "tabelas" ou "gráficos", e, por sua vez, "realidades" múltiplas, na medida em que

\section{Colaboradores}

I. Dourado, L. A. V. Silva, L. Magno, M. Lopes e C. Cerqueira contribuiram na concepção e redação do artigo, e desenho do estudo. A. Prates, S. Brignol e S. MacCarthy colaboraram na revisão da literatura, desenho do estudo e redação do artigo. são feitas/performadas usando-se articulações e "ferramentas" diversas, gostaríamos de enfatizar que a produção de conhecimento, inclusive epidemiológico, ocorre por intermédio de uma rede de mediação contínua; enfim, de negociações e participações múltiplas (de humanos, não humanos/materiais).

Reconhecer esse processo comum, ordinário, de produção de conhecimento como uma práxis social, para além das dicotomias tradicionais (natureza/cultura, objetividade/subjetividade, qualitativo/quantitativo), pode ser um movimento interessante para viabilizar práticas de pesquisa mais inter/transdisciplinares e, por conseguinte, trânsitos e diálogos (possíveis) entre os sujeitos que participam desses processos. Nesse sentido, considerando a nossa experiência no uso da metodologia RDS, gostaríamos, ainda, de destacar os seguintes aspectos: (1) a necessidade de ficarmos atentos aos contextos em que as pessoas vivem e aos significados que elas dão às suas redes sociais, o que pode demandar a articulação de diferentes estratégias de pesquisa (qualitativas e quantitativas) no decorrer de uma mesma investigação; (2) que esta experiência de pesquisa interdisciplinar, ou de metodologias "híbridas", está sujeita às circunstâncias de sua produção; (3) e, portanto, reconhecer que as "estratégias" de investigação científica não podem ser reduzidas a "modelos" fixos ou preestabelecidos.

\section{Agradecimentos}

Os autores agradecem à ATRAS/Millena Passos; ao IBCM/Padre Alfredo Dorea; a Keila Simpson e Ailton Santos pelo incentivo com o tema; a Cremildo Baptista Taciane Oliveira e Victor Souza pelas contribuições ao Projeto; a José Carlos Chaves, Fábio Queiroz, Patrícia Resende pelas contribuições durante a fase de organização da pesquisa; a Sandro Correia pela logomarca; a Ágnes Cajaíba, pelas fotos; a Breno Alexandre pelo site; ao Departamento Nacional de DST, Aids e Hepatites Virais/Ministério da Saúde. Projeto Aprovado pelo Comitê de Ética e Pesquisa da Secretaria de Saúde do Estado da Bahia. Parecer 225.943, CAAE: 07135912.7.0000.0052. 


\section{Referências}

1. Institute of Medicine. The health of lesbian, gay, bisexual, and transgender people: building a foundation for better understanding. Washington DC: National Academies Press; 2011.

2. Departamento de Apoio à Gestão Participativa, Secretaria de Gestão Estratégica e Participativa, Ministério da Saúde. Política Nacional de Saúde Integral de Lésbicas, Gays, Bissexuais, Travestis e Transexuais. Brasília: Ministério da Saúde; 2012.

3. World Health Organization. Prevention and treatment of HIV and other sexually transmitted infections among men who have sex with men and transgender populations. Geneva: World Health Organization; 2008.

4. Joint United Nations Programme on HIV/AIDS. UNAIDS Action framework: universal access for men who have sex with men and transgender people. Geneva: World Health Organization; 2009.

5. McKay B. Lesbian, gay, bisexual, and transgender health issues, disparities, and information resources. Med Ref Serv Q 2011; 30:393-401.

6. Baral SD, Poteat T, Stromdahl S, Wirtz AL, Guadamuz TE, Beyrer C. Worldwide burden of HIV in transgender women: a systematic review and meta-analysis. Lancet Infect Dis 2013; 13:214-22.

7. Cahill S, Makadon H. Sexual orientation and gender identity data collection in clinical settings and in electronic health records: a key to ending lgbt health disparities. LGBT Health 2014; 1:34-41.

8. Dos Ramos Farias MS, Garcia MN, Reynaga E, Romero M, Vaulet ML, Fermepin MR, et al. First report on sexually transmitted infections among trans (male to female transvestites, transsexuals, or transgender) and male sex workers in Argentina: high HIV, HPV, HBV, and syphilis prevalence. Int J Infect Dis 2011; 15:e635-40

9. Russi JC, Serra M, Vinoles J, Perez MT, Ruchansky D, Alonso G, et al. Sexual transmission of hepatitis $B$ virus, hepatitis $C$ virus, and human immunodeficiency virus type 1 infections among male transvestite comercial sex workers in Montevideo, Uruguay. Am J Trop Med Hyg 2003; 68:716-20.

10. MacCarthy S, Reisner SL, Nunn A, Perez-Brumer A, Operario D. The time is now: attention increases to transgender health in the United States but scientific knowledge gaps remain. LGBT Health 2015; 2:287-91.

11. Reisner SL, Bailey Z, Sevelius J. Racial/ethnic disparities in history of incarceration, experiences of victimization, and associated health indicators among transgender women in the U.S. Women Health 2014; 54:750-67.

12. Bogart LM, Revenson TA, Whitfield KE, France CR. Introduction to the special section on Lesbian, Gay, Bisexual, and Transgender (LGBT) health disparities: where we are and where we're going. Ann Behav Med 2014; 47:1-4

13. Hatzenbuehler ML, Bellatorre A, Lee Y, Finch BK, Muennig P, Fiscella K. Structural stigma and allcause mortality in sexual minority populations. Soc Sci Med 2014; 103:33-41.
14. Duncan DT, Hatzenbuehler ML. Lesbian, gay, bisexual, and transgender hate crimes and suicidality among a population-based sample of sexual-minority adolescents in Boston. Am J Public Health 2014; 104:272-8.

15. Lionço T. Atenção integral à saúde e diversidade sexual no processo transexualizador do SUS: avanços, impasses, desafios. Physis (Rio J.) 2009; 19: 43-63.

16. Arán M, Murta D, Lionço T. Transexualidade e saúde pública no Brasil. Ciênc Saúde Coletiva 2009; 14:1141-9.

17. Aran M, Murta D. Do diagnóstico de transtorno de identidade de gênero às redescrições da experiência da transexualidade: uma reflexão sobre gênero, tecnologia e saúde. Physis (Rio J.) 2009; 19:15-41.

18. Almeida G, Murta D. Reflexões sobre a possibilidade da despatologização da transexualidade e a necessidade da assistência integral à saúde de transexuais no Brasil. Sex, Salud Soc (Rio J.) 2013; (14):380-407.

19. Bento B. Sexualidade e experiências trans: do hospital à alcova. Ciênc Saúde Coletiva 2012; 17:265564.

20. Silva L. Práticas de mediação na pesquisa epidemiológica sob o ponto de vista etnográfico. Hist Ciênc Saúde-Manguinhos 2009; 16:109-28.

21. Almeida Filho N, Fernandes R, Larrea-Killinger C, Silva L. Construindo a Etnoepidemiologia. In: Almeida Filho N, Barreto M, organizadores. Epidemiologia \& saúde: fundamentos, métodos, aplicações. Rio de Janeiro: Editora Guanabara Koogan; 2011. p. 386-95.

22. Nunes M, Paim JS. Um estudo etno-epidemiologico da violência urbana na Cidade de Salvador, Bahia, Brasil: os atos de extermínio como objeto de analise. Cad Saúde Pública 2005; 21:459-68.

23. Béria JU, Damiani MF, Dos Santos IS, Lombardi C. Physicians' prescribing behaviour for diarrhoea in children: An ethnoepidemiological study in southern Brazil. Soc Sci Med 1998; 47:341-6.

24. Uchoa E, Barreto SM, Firmo JO, Guerra HL, Pimenta Jr. FG, Lima-e-Costa MFF. The control of schistosomiasis in Brazil: an ethno-epidemiological study of the effectiveness of a community mobilization program for health education. Soc Sci Med 2000; 51:1529-41.

25. Samaja J. Epistemologia e epidemiologia. In: Almeida-Filho N, Barata R, Barreto M, Veras R, organizadores. Teoria epidemiológica hoje: fundamentos, interfaces, tendências. Rio de Janeiro: Editora Fiocruz/Abrasco; 1998. p. 23-36.

26. Agar M. Recasting the "ethno" in "epidemiology". Med Anthropol 1994; 16:391-403.

27. Latour B. Reagregando o social: uma introdução à teoria do ator-rede. Salvador: Edufba; 2012.

28. Denzin NK, Lincoln YS. A disciplina e a prática da pesquisa qualitativa. In: Denzin NK, Lincoln YS, organizadores. O planejamento da pesquisa qualitativa: teorias e abordagens. Porto Alegre: Editora Artmed; 2006. p. 15-41. 
29. Latour B. Políticas da natureza: como fazer ciência na democracia. Bauru: Edusc; 2004.

30. Johnston LG, Malekinejad M, Kendall C, Iuppa IM, Rutherford GW. Implementation challenges to using respondent-driven sampling methodology for HIV biological and behavioral surveillance: field experiences in international settings. AIDS Behav 2008; 12 (4 Suppl):S131-41.

31. Malekinejad M, Johnston LG, Kendall C, Kerr LR, Rifkin MR, Rutherford GW. Using respondentdriven sampling methodology for HIV biological and behavioral surveillance in international settings: a systematic review. AIDS Behav 2008; 12(4 Suppl):S105-30.

32. Heckathorn DD. Snowball versus RespondentDriven Sampling. Sociol Methodol 2011; 41: 355-66.

33. Ramirez-Valles J, Heckathorn DD, Vazquez R, Diaz RM, Campbell RT. From networks to populations: the development and application of respondentdriven sampling among IDUs and Latino gay men. AIDS Behav 2005; 9:387-402.

34. Kerr LR, Mota RS, Kendall C, Pinho AA, Mello MB, Guimarães MD, et al. HIV among MSM in a large middle-income country. AIDS 2013; 27:427-35.

35. Szwarcwald CL, Souza Junior PR, Damacena GN, Junior AB, Kendall C. Analysis of data collected by RDS among sex workers in 10 Brazilian cities, 2009: estimation of the prevalence of HIV, variance, and design effect. J Acquir Immune Defic Syndr 2011; 57 Suppl 3:S129-35.

36. Malta M, Beyrer C. The HIV epidemic and human rights violations in Brazil. J Int AIDS Soc 2013; 16:18817.
37. Joint United Nations Programme on HIV/AIDS. United Nations Programme on HIV/AIDS (UNAIDS). Report on the global AIDS epidemic. Geneva: World Health Organization; 2006.

38. Kulick D. Sex, gender, and culture among Brazilian transgendered prostitutes. Chicago: University of Chicago Press; 1998.

39. De Oliveira NM. Damas de paus: o jogo aberto dos travestis no espelho da mulher. Salvador: Centro Editorial e Didático da UFBA; 1994.

40. Pelúcio L, Bonneti A, Fleischer S. No salto: trilhas e percalços de uma etnografia entre travestis que se prostituem. In: Bonetti A, Fleischer S, organizadores. Entre saias justas e jogos de cintura. Florianópolis: Editora Mulheres/Santa Cruz do Sul: EDUNISC; 2007. p. 93-124.

41. Pelúcio L. "Toda quebrada na plástica”: corporalidade e construção de gênero entre travestis paulistas. CAMPOS - Revista de Antropologia Social 2005; 6:97-112.

42. Pelúcio LM. Travestis, a (re)construção do feminino: gênero, corpo e sexualidade em um espaço ambíguo. Revista Anthropológicas 2011; 15:12354 .

43. Benedetti MR. Toda feita: o corpo e o gênero das travestis. Rio de Janeiro: Editora Garamond; 2005.

44. Turkle S. Cyberspace and identity. Contemporary Sociology 1999; 28:643-8.

45. Miller D, Slater D. Etnografia on e off-line: cibercafés em Trinidad. Horizontes Antropológicos 2004; 10:41-65.

46. Knorr-Cetina K. Epistemic cultures: how the sciences make knowledge. Cambridge: Harvard University Press; 1999.

47. Mol A. Ontological politics. A word and some questions. Sociol Rev 1999; 47:74-89. 


\section{Abstract}

Trans persons, including transvestites and transsexual women, show disproportionately high HIVIAIDS rates when compared to the rest of the population. However, few quantitative/qualitative studies have addressed trans persons in Brazil. Thus, a team of researchers from different fields is developing an interdisciplinary research project with the objective of shedding light on living conditions and ways of life among transvestites and transsexual women, while investigating determinant factors for HIV infection, syphilis, and hepatitis $B$ and $C$. The article is intended to describe the experience with the implementation and development of an ethno-epidemiological study in Salvador, Bahia State, Brazil. Mapping the population began with a formative survey that was crucial for orienting the epidemiological survey. The production of ethno-epidemiological data posed a daily challenge for the researchers, triggering a series of reflections on the limits of our concepts and categories for translating the diversity of study participants' practices and experiences.

Transgender Persons; HIV; Acquired Immunodeficiency Syndrome; Interdisciplinary Research

\section{Resumen}

Personas transexuales, incluyendo travestis, mujeres transexuales, presentan tasas desproporcionalmente elevadas de VIH/SIDA, en comparación con el resto de la población. No obstante, son pocos los estudios cuantitativos/cualitativos con personas transexuales en Brasil. Por ello, un equipo de investigadores de diferentes áreas desarrolla un proyecto de investigación interdisciplinaria, con el fin de conocer las condiciones y modos de vida, y al mismo tiempo investigar factores determinantes de la infección por el VIH, sífilis y hepatitis B y C entre travestis y mujeres transexuales. En este artículo se pretende describir la experiencia de la implantación y desarrollo del estudio con un enfoque etnoepidemiológico en Salvador, Bahía, Brasil. El mapeo de la población comenzó con una investigación formativa que fue crucial para orientar la encuesta epidemiológica. La producción de datos etnoepidemiológicos se muestra como un desafío cotidiano para los investigadores, produciendo una serie de reflexiones sobre los límites de nuestros conceptos y categorías para traducir la diversidad de prácticas y experiencias de las participantes de la investigación.

Personas Transgénero; VIH; Síndrome de Inmunodeficiencia Adquirida; Investigación Interdisciplinaria
Recebido em 03/Nov/2015

Versão final reapresentada em 27/Abr/2016 Aprovado em 08/Jul/2016 